\title{
SOURCES OF PROFESSIONAL STAFF TURNOVER IN PUBLIC ACCOUNTING FIRMS REVEALED BY THE EXIT INTERVIEW ${ }^{1}$
}

\author{
JOHN GRANT RHODE \\ University of California, Berkeley \\ JAMES E. SORENSEN \\ University of Denver \\ EDWARD E. LAWLER III \\ University of Michigan and Battelle Memorial Institute \\ With the assistance of
}

KENNETH A. MERCHANT, GREGORY D. JACOBSON and RONALD E. DUNGEY

\begin{abstract}
Employee and employer stated reasons for leaving public accounting were studied together with the conditions surrounding departure and the best and least liked qualities of CPA firm work. Data collected after employee terminations on selected aspects of the work was shown to be a good predictor of whether employees left of their own volition or at the request of the firm and revealed several areas suitable for improving personnel relationships and reducing professional staff turnover.
\end{abstract}

The personnel function is a major part of administrative operations at most large Certified Public Accounting (CPA) firms since substantial amounts of time and money are expended in recruiting and training staff accountants. Because the CPA profession is dependent on retaining high quality personnel, it has become rather conscious of the turnover problems within its ranks. There is increasing awareness that professional staff turnover in public accounting is high relative to other professions (Grossman, 1967; Kollaritsch, 1968; Capin, 1969; Farris, 1971), and a developing literature on the personnel aspect of the public accounting profession has resulted (Cruse, 1965; DeCoster \& Rhode, 1971; Istvan, 1973; Leathers, 1971; Sorensen, 1967; Ashworth, 1968). But, unfortunately, little research has been done to determine the exact causes of tumover. Half (1968) states that the most important reason why people in accounting change jobs is to gain respect. There are very likely other reasons for turnover in public accounting. This report attempts to identify those reasons by focusing on exit interview data obtained when individuals leave their initial employment position with a CPA firm.

In response to the need for more complete information concerning professional staff turnover in public accounting, a turnover study was commissioned. This is an on-going study designed to identify the causal factors influencing turnover by systematically examining various characteristics and attitudes of individuals who enter public

\footnotetext{
${ }^{1}$ This study is sponsored jointly by the American Institute of Certified Public Accountants (AICPA) and several of the largest international Certified Public Accounting (CPA) firms. A Commission, comprised of representatives of the AICPA and CPA firms participating financially in the project, meets periodically with the researchers to serve in an advisory capacity and to appraise the progress of the study. Although the CPA firms represented on the Commission and the AICPA have funded the research project, all of the research findings and interpretations are the responsibility of the authors, and accordingly, commentary on the research should be directed to the authors.
} 
accounting. A sample of individuals is being followed starting 1 year prior to employment in public accounting and continuing through the first several years of their careers.

Other reports from this study have examined the biographical backgrounds, personality and vocational interest test scores (Rhode, Sorensen \& Lawler, 1976) of the individuals in the sample, the emergence of an increasing generation gap in attitudes between entry level staff accountants and experienced CPA firm supervisory personnel (Sorensen, Rhode \& Lawler, 1973), and the job choice and post-decision dissonance (Lawler, Kuleck, Rhode \& Sorensen, 1975) of the sample group. At this time, a sufficient number of the subjects in the study have left the accounting firms where they were originally employed to allow an initial analysis of their reasons for the turnover.

This report will examine the responses of the individuals who left their firms of original employment of their own volition and compare them with the responses of those who left their firms original employment at the request of their employer. The purpose of this comparison is to see if there are any significant differences between the two groups which might indicate factors which influence turnover. Professional staff turnover is of two types - that which occurs when individuals who the CPA firm would like to retain decide to leave (left of their own volition), and that which results when individuals leave because their employing CPA firm no longer desires their employment (left at request of CPA firm).

The individuals who leave of their own volition comprise the group which most concerns the accounting firms. Although the CPA firms would like to recruit entry-level staff accountants in such a way as to avoid hiring someone who they will later ask to leave, it is probably not these persons from which the firms feel the most loss. Rather, the greatest loss to the CPA firms results from losing the persons who left of their own volition. The firms want these individuals to remain and fulfil some demonstrated potential to succeed. Since these are also most likely the personnel whom the CPA firms are counting on to draw their partners from to someday manage their practice, the loss of experience from those who leave of their own volition could be substantial in the years to come.

The results of this report will, hopefully, provide a basis to predict the conditions and attitudes which can cause or prevent turnover.
Knowledge of these conditions and attitudes could then be used by CPA firms to improve the effectiveness of their selection procedures and administrative practices since turnover has been blamed, in part, on an inadequate selection process (Ellyson \& Shaw, 1970). Also, analysis of these conditions may be useful in the active retention efforts of those proven employees the firm wishes to retain. In addition, the report should be of counseling benefit to those staff accountants who are currently employed in CPA firms and for those students who are considering a career in public accounting by indicating a data-based approach to the reasons why staff accountants decide to leave their initial public accounting employers.

\section{Methodology}

Two related aspects of the turnover problem employee and employer stated conditions for leaving public accounting, and, evaluative statements about the work itself - are analyzed in this report. The scope is limited to responses from subjects who terminated within the first $3 \frac{1}{2}$ years of public accounting employment $(N=99)$ and all subjects $(N=200)$ who indicated what they liked best and least about their work in public accounting prior to termination.

All of the 99 subjects who terminated returned their exit interview questionnaires within a few months after their termination date. Yet, as shown in Table 1, responses from CPA firms were not as complete. The firms returned questionnaires on 92 of the 99 terminated employees, again within a short time after the subjects terminated. The questionnaires were sent to CPA firms with the request that a person of supervisory experience familiar with the terminated employees' work should complete the exit questionnaire. Periodic monitoring of employment status facilitated a mailing of the exit interview questionnaires to terminated employees and their employers shortly after subjects left firms of original employment.

Both the CPA firm employers and terminated subjects provided a single objective statement surrounding the subjects' departure when asked to identify which of six conditions best described the relationship between the individual and the firm at the time of termination:

What were the conditions surrounding your departure from your former CPA employer?

Released with little notice, 
TABLE 1. Exit questionnaire response data

\begin{tabular}{lccccc}
\hline & \multicolumn{2}{c}{ Individual } & \multicolumn{2}{c}{ Firm } \\
& $N$ & $\%$ & & \multicolumn{1}{c}{$N$} & $\%$ \\
\hline $\begin{array}{l}\text { Questionnaire completed by } \\
\text { individuals and CPA firms }\end{array}$ & 92 & 93 & & 92 & 100 \\
$\begin{array}{l}\text { Questionnaire completed by } \\
\text { individuals and not } \\
\text { completed by CPA firms }\end{array}$ & $\underline{7}$ & $\underline{7}$ & & - & - \\
Totals & $\underline{99}$ & $\underline{100}$ & & $\underline{92}$ & $\underline{100}$ \\
\hline
\end{tabular}

Encouraged to leave as soon as possible,

Encouraged to stay for a limited time (e.g. less than a year),

Encouraged to stay; career outcome with the firm was uncertain,

Encouraged to stay; promotion appeared likely but not including manager or partner, and

Encouraged to stay; promotion appeared likely including positions such as manager or partner.

These conditions were viewed as divisible into two categories. The individuals who were placed in one of the last three categories were classified as leaving of their own volition. These are individuals whom the CPA firms wished to further employ, but for some reason, the individuals wanted to leave despite efforts to retain them. Individuals from the sample group who were placed in this category are referred to throughout the report as having left of their own volition and individuals who were placed in the first three categories are described as leaving at the request of the firm.

The classification of the sample group into the two categories is not as simple as it would appear, as the individuals and the firms did not always agree on the conditions surrounding an employee's leave-taking. Table 2 shows the levels of agreement and disagreement between the individual and the firm as to the category which best described their relationship at the time of the exit interview. From these data, it may be inferred that $19.5 \%$ (quadrants II and III) of the individuals had misconceptions as to the status of their leavetaking. These misconceptions say something about the validity of the exit interview employed by CPA firms when some $14 \%$ of the sample group

TABLE 2. Correspondence between employee and employer reasons for turnover

\begin{tabular}{|c|c|c|c|c|c|c|c|}
\hline & & & & $\begin{array}{l}\text { Leave } \\
\text { ted by }\end{array}$ & $\begin{array}{l}\text { king a } \\
\text { e emp }\end{array}$ & & \\
\hline & & & $\begin{array}{l}t \text { at } \\
\text { lest } \\
\mathrm{rm}\end{array}$ & & $\begin{array}{l}t \text { of } \\
\text { own } \\
\text { tion }\end{array}$ & & tals \\
\hline & $\begin{array}{l}\text { Left at } \\
\text { request }\end{array}$ & $N$ & $\%$ & $N$ & $\%$ & $N$ & $\%$ \\
\hline & of firm & 23 & 25.0 & 13 & 14.1 & 36 & 39.1 \\
\hline $\begin{array}{l}\text { Leave-taking } \\
\text { as stated by }\end{array}$ & & & I & II & & & \\
\hline the firm & & & III & IV & & & \\
\hline & $\begin{array}{l}\text { Left of } \\
\text { their own } \\
\text { volition }\end{array}$ & 5 & 5.4 & 51 & 55.5 & 56 & 60.9 \\
\hline & Totals & 28 & 30.4 & 64 & 69.6 & 92 & 100.0 \\
\hline
\end{tabular}


felt they left of their own volition and were, indeed, leaving at the request of the firm. This is somewhat understandable since the CPA firms, attempting to maintain a favorable relationship with terminated staff accountants, may have indicated to their employees that they left under more favorable circumstances than actually occurred. What is not as easily understood is how some $5 \%$ of the sample group assumed they left at the request of their employing firm, and yet the CPA firm indicated that they left of their own volition. For these individuals, a serious communication gap, or misunderstanding, surrounded the perception of their leave-taking. Fortunately, less than $6 \%$ were so affected.

Because of the significance of this misunderstanding, the groups will be analyzed based on both the employee and employer reasons for leaving so as to provide comparative views of the turnover situation. The comparisons will be made by means of statistically testing two hypotheses.

\section{Statement of hypotheses}

In keeping with the format established in earlier reports of the Turnover Study, the following null hypotheses have been established to test for statistically significant differences in the data:

Hypothesis No. 1. There are no differences in the rated importance of reasons for leaving CPA firms of original employment between employees who say they left of their own volition and employees who say they left at the request of the firm.

Hypothesis No. 2. There are no differences in the rated importance of reasons for leaving CPA firms of original employment between employees whose firms say they left of their own volition and whose firms say they left at the request of the firm.

The first hypothesis compares groups selected from the total sample according to the subjects' own classification of his or her relationship to the firm at the time of termination. This analysis uses data from all 99 questionnaires received for the comparison between those who left of their own volition $(N=68)$ and at the request of the firm $(N=31)$. The second hypothesis bases the classification of the groups on the responses given by the firms. There were 92 questionnaires received from the firms, 57 representing individuals who left of their own volition and 35 considered to have left at the request of the firm as stated by the employcrs.

The 39 selected reasons (see Table 3) for leaving the firm were rated by each individual in the total sample according to the importance of each reason on a scale from 1 (not important) to 5 (extremely important). These reasons formed the variables for the analysis. Several procedures were used in the analysis of these data. An $F$-ratio was used to calculate the level of significance for each of the 39 questions. The " $t$ "-test and Tilton overlap indices were also calculated. According to Hays (1963), the " $t$ "-test for mean differences lends itself well for univariate analysis, and coupled with the Tilton (1937) overlap statistic, a combined inference may be derived. The Tilton overlap statistics expressed in percentage form the amount of similarity between two sample groups. When the percentage is high, showing much overlap, the significance of a high " $t$ " score is diminished.

Because the responses to the 39 Table 3 questions might be related, factor analysis was used to analyze the intercorrelations. Independent dimensions or constructs of the reasons for turnover were then determined for comparison between groups who left of their own volition and those who left at the request of their employer.

\section{Analysis of results}

A note of caution should be stated when interpreting the results of this report because the Turnover Study does not deal in absolutes, but

TABLE 4. Factor analysis of employer-stated-reasons for employees leaving public accounting

\begin{tabular}{lcllll}
\hline & Factor & & Title & Variables (loading) & $\begin{array}{c}\text { Cum. variance } \\
\text { explained, \% }\end{array}$ \\
\hline $\begin{array}{l}\text { Total } \\
\text { Sample }\end{array}$ & I & Uncertainty about job requirements & $12(.70), 2(.68), 7(.66), 10(.64)$, & 37.8 \\
$N=92$ & II & Workload too heavy & $8(.57), 35(.56), 5(.51)$ & $21(.84), 4(.79), 11(.74), 15(.69)$, & 53.2 \\
& III & Geographical preferences & $39(.52)$ & $27(.77), 26(.72), 28(.72), 29(.52)$ & 64.5 \\
\hline
\end{tabular}



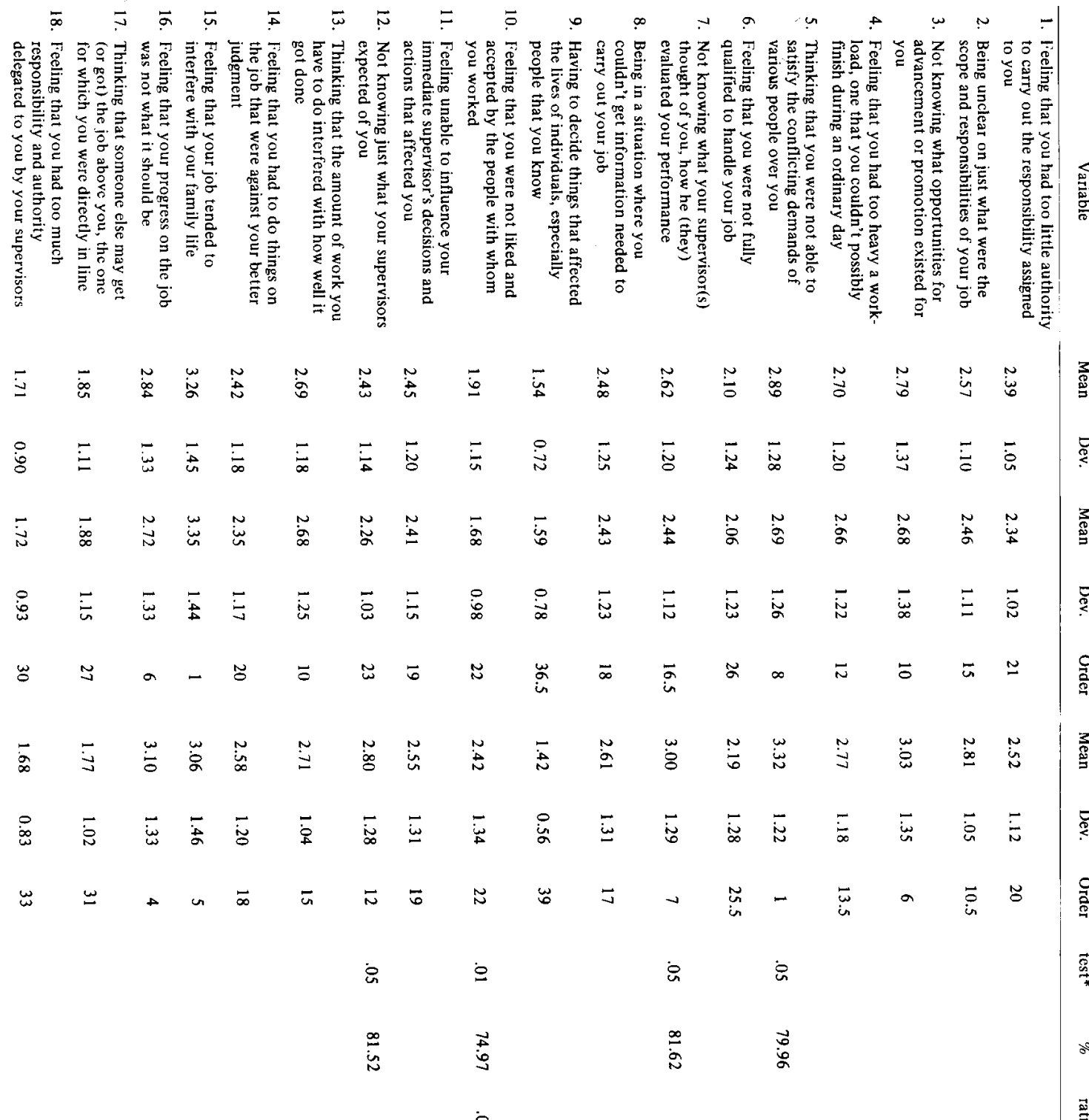

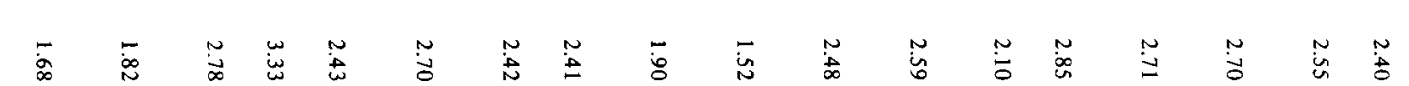

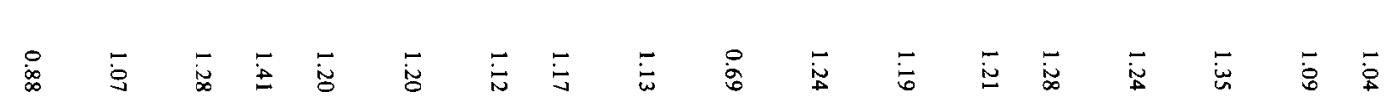

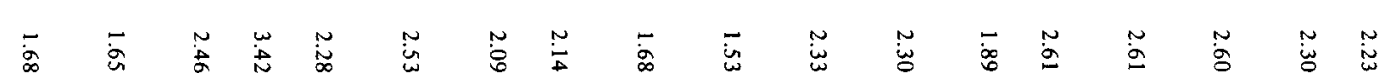

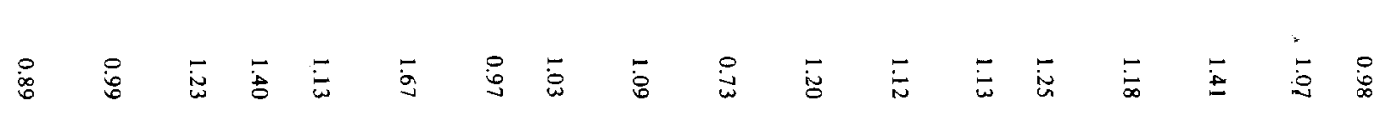

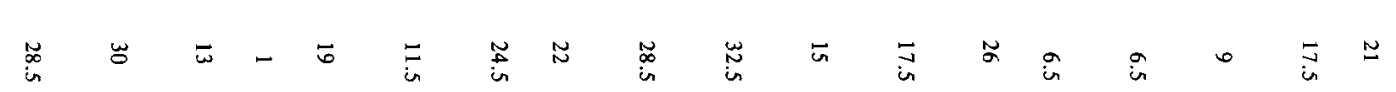

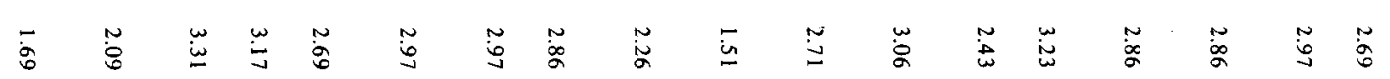

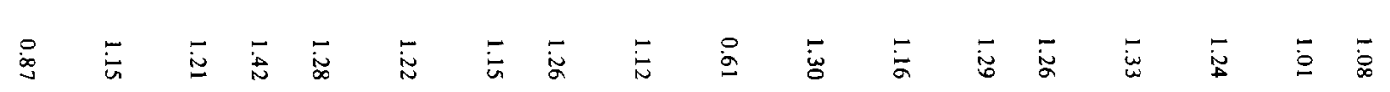

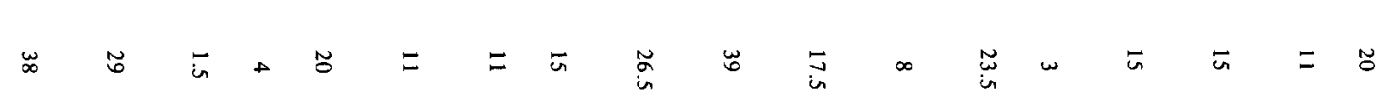

\begin{tabular}{|c|c|c|c|c|c|c|c|c|}
\hline & $\stackrel{\circ}{\circ}$ & $\ddot{s}$ & $\stackrel{9}{ }$ & is & i & & $\ddot{q}$ & $\frac{\overrightarrow{0}}{3}=$ \\
\hline & $\begin{array}{ll}\vec{\omega} & \vec{\omega} \\
\stackrel{\omega}{\omega}\end{array}$ & $\begin{array}{l}\overrightarrow{0} \\
\stackrel{\omega}{\omega}\end{array}$ & $\begin{array}{l}\vec{\omega} \\
\dot{0} 0 \\
\dot{0}\end{array}$ & 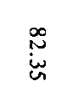 & 象 & $\underset{\stackrel{\vec{\omega}}{\omega}}{\vec{\omega}}$ & 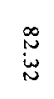 & 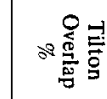 \\
\hline
\end{tabular}




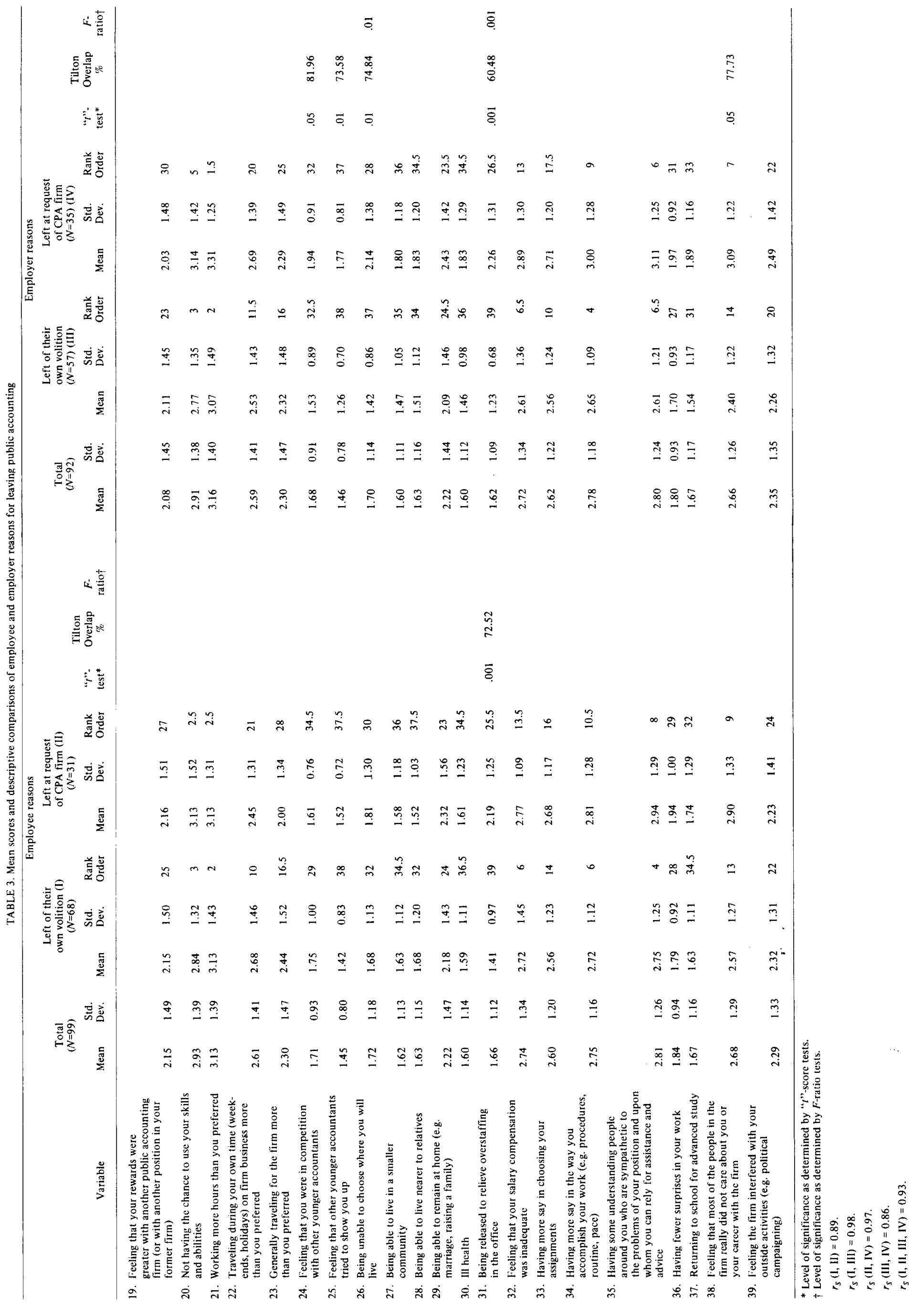


rather in relatives of group characteristics. The descriptive statistics, " $t$ "-tests, and the Tilton overlap results are shown in Table 3 together with a rank order for the mean value of each reason for turnover. This analysis indicates that there are interesting relationships between the Tilton overlap and the " $t$ "-test analysis and that these relationships should be considered carefully before placing meaning to the data. Only when the Tilton overlap was below $80 \%$ and the " $t$ "-test result less than 0.01 level of significance was there a corresponding $F$-ratio result of at least a 0.05 level of significance. Keeping these precautions in perspective, these data can impart considerable information. Again, the results are not representative of any one individual but express group characteristics.

\section{RESULTS AND DISCUSSION}

\section{Factor analysis}

Table 4 presents the results from the factor analysis of the 39 items. The analysis yielded three factors which account for $64.5 \%$ of the variance. The first factor - uncertainty about job requirements - seems to contain items which are concerned with job definition and support. High scores on these items indicate that lack of a clear idea of what to do and less support than desired to get the job done contribute to the intensity of the first factor. Indeed, only the items on Factor 1 truly differentiate between the voluntary and involuntary turnover groups. The second factor workload too heavy - contains items which are largely concerned with the amount of work required, and the third factor - geographical preference - contains ilems primarily expressing a change in location.

\section{HYPOTHESIS NO. 1}

Five of the 39 reasons for leaving, when analyzed on a univariate basis, did reveal some statistically significant and interesting comparisons. Yet, none of the Tilton overlap percentages for the mean comparisons are less than $72 \%$ indicating a considerable amount of overlap or similarity. The statistically significant differences between those leaving of their own volition and at the request of the firm are pointed out by the $F$-ratio analysis (Variables 5, 7, 10, 12 and 31). On each of these comparisons, the group stating they left at the request of the firm had a higher mean score than did the group stating they left of their own volition. Moreover, because items 5, 7, 10 and 12 all appear on Factor 1, that factor provides a fairly reliable discriminator between the two groups.

Thinking that they were not able to satisfy the conflicting demands of various supervisory people over them (Variable 5), yielded a significant difference $(p<0.05)$ between the two groups with those indicating they left at the request of the firm saying it was more important in causing them to turnover.

Not knowing what your supervisors thought of you and how they evaluated your performance (Variable 7$)$ is statistically significant $(p<0.05)$ as is not knowing just what your supervisors expected of you (Variable 12). These variables all load on Factor I as does Variable 5 (thinking that you were not able to satisfy the conflicting demands of various people over you) which is also statistically significant. Not knowing how one is evaluated by superiors and not knowing what performance is expected can have a strong negative influence on performance. Consequently, it is not surprising that individuals with these feelings were more likely to be asked to leave by their CPA firms.

Variable 10 (feeling that you were not liked and accepted by the people with whom you worked) also indicates a statistically significant $(p<0.01)$ difference between the two groups. Feeling that you are not liked and accepted by the people with whom you work is also a strong destructive feeling so far as performance is concerned. Those leaving of their own volition seem more secure in their feelings and relationships with their fellow workers, even if the feelings are not entirely positive, while those leaving at the request of their firms are more insecure in their relationships as evidenced by their higher mean score on Variable 10. Thus, an overall pattern exists in that those who are let go by their firms are stating that uncertainty about job requirements and poor support were rather important in causing them to turnover.

Being released to relieve over-staffing in the office (Variable 31) provides an interesting contrast for the two groups. It has a high level of significance, even though it did not load on any general factor. Because of the peculiarity it holds for those leaving at the request of the firm, the 
staff accountants being asked to leave probably identify with this socially acceptable reason more easily than those who are leaving of their own volition. It would be unusual for someone, who would be able to stay with their firm even at a time of staff reductions, to voluntarily leave to help relieve overstaffing - particularly given the lack of attractive alternative professional positions in the currently tight job market. Indeed, this variable may work better as an example of predictive hindsight. Perhaps the firm's real interest is to terminate certain staff or reduce expenses, but the individual is encouraged to go elsewhere where the opportunities are better because promotions at the CPA firm will be slow for everyone due to over-staffing. Whatever the appearances, this reason is the popular one for those who leave at the request of the firm. It is also a neutral reason. Neither is the person to blame for inadequatc performance, nor is the firm at fault for less than the best working conditions. Consequently, this reason is easy for both parties to accept because it doesn't pertain to egoinvolvement for either the employee or employer.

Three other items emphasize the lack of clear understanding for work requirements and deficiencies in the organizational system. Being unclear about scope and responsibilities (Variable 2), being in a situation where you cannot get needed information (Variable 8) and not having understanding and sympathetic support (Variable 35) all reinforce these potential problem areas in CPA personnel administration.

Also of interest is the ranked similarity of reasons for leaving between the comparison groups tested under Hypothesis No. 1. With a Spearman rank correlation coefficient (Siegel, 1956), as indicated in Table 3, of 0.89 , there is a substantial amount of ranked agreement among the reasons for turnover - even though some variables $(5,7$, 10 and 12) differentiate rather nicely between the two groups. This indicates that the least preferable aspects of public accounting work are still fairly persuasive. Four of the seven top ranked variables $(15,16,20$ and 21$)$ are similar, and seven of the top ten $(3,5,15,16,20,21,35)$ are the same for the two groups.

The seven highest ranked reasons for turnover, according to those who left of their own volition, are perhaps the most important data in this report (Variables 15, 21, 20, 35, 16, 32, 34) since these are the primary reasons why CPA firms are not retaining the employees which they most want to keep - the staff accountants who leave of their own volition.

\section{HYPOTHESIS NO. 2}

The univariate comparisons of this analysis reveals that there are more variables (fourteen in total) which are statistically significant than for the testing of Hypothesis No. 1. Again, all the significant variables show higher scores for those who are asked to leave by the firm. The variables which are significant appear to have a great deal in common. Most of the items from factor I are significant. The variables which were shown to be significant appear to have some qualities in common. Variables 2 (being unclear on just what were the scope and responsibilities of your job), 7 [not knowing what your supervisor(s) thought of you, how he (they) evaluated your performance] and 12 (not knowing just what your supervisors expected of you) all reveal some job-related uncertainty that may lead to poor performance and dismissal.

Variables 1 (feeling that you had too little authority to carry out the responsibility assigned to you) and 11 (feeling unable to influence your immediate supervisor's decisions and actions that affected you) deal with a feeling of professional inadequacy which can also cause staff frustration. These conditions might be relieved by improving the job design and communications in CPA firms so that individuals will be better able to perform their jobs.

A number of additional performance related variables, 6 (feeling that you were not fully qualified to handle your job), 24 (feeling that you were in competition with other younger accountants), 38 (feeling that most of the people in the firm really did not care about you or your career with the firm), 10 (feeling that you were not liked and accepted by the people with whom you worked), 16 (feeling that your progress on the job was not what it should be), and 25 (feeling that other younger accountants tried to show you up), were statistically significant. All of these were rated as more important by the group asked to leave at the firm's request. Since these variables are either related to performance or work relationships, they fit with the general pattern of this group being characterized by poor job conditions or poor performance. Yet, each of these variables should be treated independently since they do not 
sufficiently relate to one another to emerge as a factor analysis determined group of items.

Despite the statistically significant univariate analysis mean differences, there remains a substantial amount of rank-ordered correlation $\left(r_{s}=0.86\right)$ for the comparison groups tested under Hypothesis No. 2. The coefficient of concordance (Siegel, 1956) for all ranks tested under both hypotheses is 0.93 - a considerable agreement among the importance of the reasons for turnover. As expected the greatest agreement is among those leaving of their own volition $\left(r_{s}=0.98\right)$ and those leaving at the request of the firm $\left(r_{s}=0.97\right)$ when a comparison is made of reasons stated by the employees and employers.

\section{Prediction of leave-taking status}

To test the ability of the 39 employee and employer stated reasons for leaving public accounting to distinguish among the terminated employees, a multivariate discriminant function analysis (Cooley \& Lohnes, 1971) was used to predict group membership. Discriminant analysis is an iterative process which assigns individuals to one group or another based on maximum intergroup variance and minimum intragroup variance of raw data scores. This technique obviates the effect of such moderator variables as biographical and demographical characteristics since the only data in the analysis are the individual responses to the thirty-nine questions. Correct predictions for each type of turnover - left at their own volition (voluntary), or left at the request of the CPA firm (involuntary) are indicated as hits in Tables 5 and 6.

The overall hit rate is $86 \%$ for the employeestated reasons for leaving with 85 of 99 predictions accurately made and $87 \%$ for the employer-stated reasons with 80 of 92 correct predictions. Both Tables 5 and 6 reveal highly successful discriminant analysis predictions well above the levels expected from chance. For the employee-stated reasons $(N=99)$, a random or chance assignment would allow a hit-rate of $57 \%$

TABLE 5. Discriminant analysis predictions for conditions surrounding departure as stated by employee

\begin{tabular}{lcccc}
\hline \multicolumn{1}{c}{ Predictions } & & $N$ & \multicolumn{2}{c}{$\%$} \\
\hline Voluntary predicted as voluntary & $(59)$ & & 92 & \\
Voluntary predicted as involuntary & & 9 & & 26 \\
Involuntary predicted as voluntary & 5 & & 8 & \\
Involuntary predicted as involuntary & $\frac{(26)}{64}$ & $\frac{35}{100}$ & $\frac{74}{100}$ \\
\hline
\end{tabular}

$x^{2}=50.919, p<0.001$, critical value $=10.83$.

Successful predictions are in parentheses ( ).

Overall successful predictions $N=85 / 99=86 \%$.

TABLE 6. Discriminant analysis predictions for conditions surrounding departure as stated by employer

\begin{tabular}{lccccc}
\hline \multicolumn{1}{c}{ Predictions } & $N$ & \multicolumn{2}{c}{$\%$} \\
\hline Voluntary predicted as voluntary & $(51)$ & & 89 & \\
Voluntary predicted as involuntary & & 6 & & 17 \\
$\begin{array}{l}\text { Involuntary predicted as voluntary } \\
\text { Involuntary predicted as involuntary }\end{array}$ & 6 & & 11 & \\
& & 57 & $\frac{(29)}{35}$ & $\frac{100}{100}$ & $\frac{83}{100}$ \\
\hline
\end{tabular}

$\chi^{2}=50.261, p<0.001$, critical value $=10.83$.

Successful predictions are in parentheses ().

Overall successful predictions $N=80 / 92=87 \%$. 
$\left[(68 / 99)^{2}+(31 / 99)^{2}\right]$ and for employer-stated reasons $(N=92)$, the chance prediction would be $53 \%\left[(57 / 92)^{2}+(35 / 92)^{2}\right]$ (Frank, Massey \& Morisson, 1965). Although it would have been preferable to predict on the basis of a hold-out sample, the low number of involuntary terminations $(N=35)$ did not warrant such an approach. As a result, the discriminant function analysis primarily indicates that the 39 reasons for leaving differentiate between the two groups at a substantial rate. As more individuals leave their public accounting employers, prediction of leavetaking status will be done with cross-validation. To cross-validate at this time would be numerically premature.

\section{Best and least liked qualities about public accounting}

Each participant in the turnover study was also asked to describe the qualities they liked best and liked least about public accounting work. These replies were categorized and are shown in Table 7. In some instances there are more replies than subjects because of multiple responses.

Two items of significance present themselves from these data. First, there is not much difference between rankings of these qualities by the different responding groups. The rank correlation statistics presented in Table 7 show a high degree of agreement, with no noticeable consistent differences between the employee and employer stated reasons for leave-taking.

Second, the CPA firms can best respond to the congruence between the attitude of their employees by designing their work environment to emphasize the best-liked qualities and minimize the least-liked qualities. Staff accountants most liked the variety in their work situations, and the firms can use their staff assignment process to provide or maintain this variety. The next most popular feature of public accounting work is the resulting personal development, and firm policies and procedures should similarly encourage this well-liked aspect of the work.

By far the most commonly mentioned negative quality was that of dull work. Perhaps some of this is inevitable for purposes of thorough training, but the firms should recognize the possible negative effects on staff morale. The dull work might be reduced through procedural changes, use of more statistical sampling assistance or employment of paraprofessionals for certain highly detailed work assignments. Other commonly mentioned detractors are the work hours, budget pressures and office politics. These undesirable work characteristics can be reduced somewhat by better planning and scheduling, staffing procedures and office rules.

\section{Summary and conclusion}

This study examined the reasons for turnover in public accounting as stated by employees and employers. Using responses from the 39 attitude questions asked, it was demonstrated that a discriminant analysis was rather successful in predicting whether individuals would leave of their own volition or at the request of their CPA firm employer.

According to Zweig (1969), the key to obtaining good personnel is consideration for individuals and their personal interests. An earlier article demonstrated that a gap in professionrelated attitudes (Sorensen, Rhode \& Lawler, 1973) exists between those who do the hiring, the managers and partners, and those staff accountants entering the profession. The present study carries that analysis further by suggesting that one of the consequences of this gap may be the failure of the CPA firms to effectively communicate with and relate to new employees. Some affirmation of the communication gap between staff accountants and their CPA firm employers is evidenced by the data in Table 2 where almost $20 \%$ of the sample group indicate a leave-taking status completely different from the employer stated reasons for turnover.

The analysis of the 39 selected reasons for leaving CPA firms also support the view that poor communication exists and is somewhat destructive of the job performance for many individuals. These variables showed that individuals being asked to leave the firm have a significant concern about their relationships with their supervisors and fellow workers. Perhaps this indicates that the staff accountants are not being incorporated into the CPA firms as full members of the family, and, despite the extensive formal evaluations, they are placed in a position of having to prove themselves without sufficient tools, clear job descriptions, and reasonable job demands. This suggests that CPA firms can reduce turnover - particularly that occurring because staff accountants are poor performers - by concentrating on improving the work and supervisory relationships cited in Table 3 as distinguishing voluntary from firm initiated turnovers. Firms focusing on these relationships may well find a significant reduction in the 


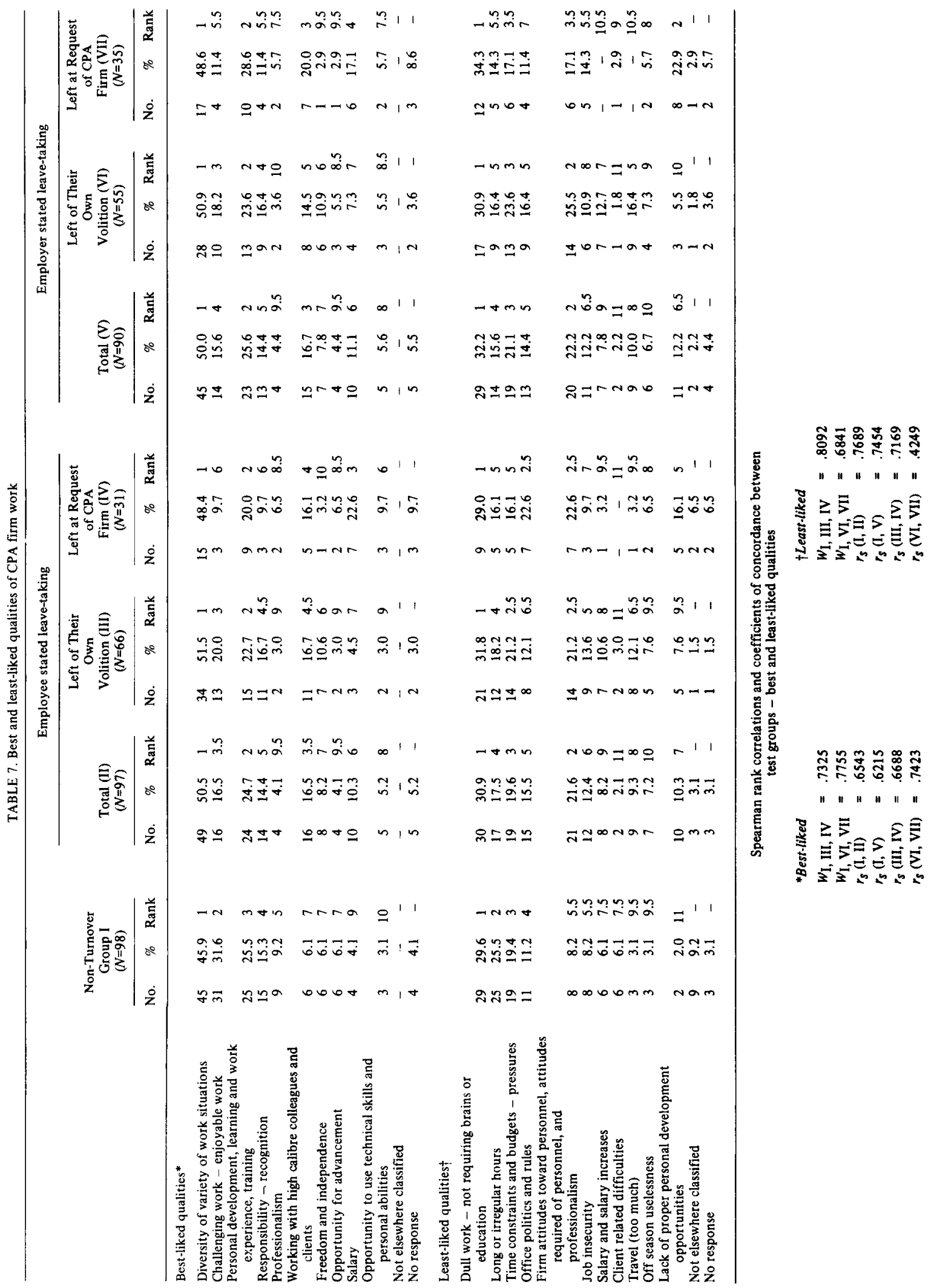


number of employees who fail to perform well and, as a result, are involuntarily released.

Employees who are let go by their firms may be simply rationalizing their dismissal by blaming the firm for poor job support. There is no way to determine from our data if this is true. It is worth noting, however, that the consistency of the data from this and other studies argues for the view that in many cases, organizations are failing the poor performers.

It is surprising that none of the thirty-nine Table 3 items were rated as significantly more important by the voluntary turnover group. One possible explanation for this is that the turnover reasons which were more important to them werc not measured by the 39 items. For example, it may be that some of the individuals who left voluntarily intended to leave all along after they fulfilled their CPA requirements and that their departures signified this rather than any job related problems. Probably the most meaningful way to determine why this group left is to compare them with those employees who stayed in terms of their pre-termination attitudes and intentions. This will be done in future reports of the turnover study. So far as the present analyses are concerned we seem to have learned mainly about what factors contribute to people being terminated by CPA firms. Here the data clearly suggest that when this occurs, the firm may have to share at least part of the blame for the poor performance which precipitated the dismissal.

The data analyzed represent open and legitimate concerns from a selected group of staff accountants during the first $3 \frac{1 / 2}{2}$ years of professional employment. Their concerns are objectively reported and do not represent what someone suspects is the cause of turnover. They are the reasons for turnover actually experienced by staff personnel. It is now up to the CPA firms to act individually to remedy their unwanted staff losses. This can be done if CPA firms can increase the positive aspects of their work environments and minimize the negative aspects. These data will, hopefully, provide a starting point.

\section{BIBLIOGRAPHY}

Ashworth, John, People Who Become Accountants, Journal of Accountancy (November, 1968), pp. 43-49.

Capin, R.S., How to Cope with the Staff Man Shortage, The Practical Accountant (March-April, 1969), p. 22.

Cooley, William W. \& Lohnes, Paul R., Multivariate Data Analysis (New York: Wiley, 1971).

Cruse, Rex, What Can the Behavioral Sciences Contribute to the Selection of CPA's, Journal of Accountancy (November, 1965), pp. 85-89.

DeCoster, Don T. \& Rhode, John Grant, The Accountants' Stereotype: Real or Imagined, Deserved or Unwarranted, The Accounting Review (October, 1971), pp. 651-655.

Ellyson, R. C. \& Shaw, B. A., The Psycholugical Assessment and Staff Recruiting, Journal of Accountancy (March, 1970), pp. 35-42.

Farris, George F., A Predictive Study of Turnover, Personnel Psychology (Summer, 1971), pp. 311-323.

Frank, Ronald E., Massy, William F. \& Morrison, Donald G., Bias in Multiple Discriminant Analysis, Journal of Marketing Research (August, 1965), pp. 250-258.

Grossman, H. I., Public Accounting Employee Turnover, Report to the Annual Meeting of the American Institute of Certified Public Accounts. New York (1967).

Half, Robert, Employees Retention in Public Accounting, The New York Certified Public Accountant (December, 1968), pp. 847-854.

Hays, William L., Statistics for Psychologists (New York: Holt, Rinehart \& Winston, 1963).

Istvan, Donald F., Improving Personnel Selection, Journal of Accountancy (February, 1973), pp. $35-40$.

Kollaritsch, F. P., Job Migration Pattern of Accounting, Management Accounting (September, 1968), pp. 52-55.

Lawler, E. E. III, Kuleck, W. J. Jr., Rhode, J. G. \& Sorensen, J. E., Job Choice and Post Decision Dissonance, Organizational Behavior and Human Performance (1975), pp. 133-145.

Leathers, Park E., Staff Retention in Public Accounting Firms, Journal of Accountancy (January, 1971), pp. 87-90.

Rhode, J. G., Sorensen, J. E. \& Lawler, E. E. III., An Analysis of Personal Characteristics Related to Professional Staff Turnover in Public Accounting Firms, Decision Sciences (1976), pp. 771-800.

Siegel, Sidney, Nonparametric Statistics for the Behavioral Sciences (New York: McGraw-Hill, 1956). 
Sorensen, J. E., Professional and Bureaucratic Organization in Large Accounting Firms, The Accounting Review (July, 1967), pp. 553-565.

Sorensen, J. E., Rhode, J. G. \& Lawler, E. E. III., The Generation Gap in Public Accounting, The Journal of Accountancy (December, 1973), pp. 42-50.

Tilton, J. W., The Measurement of Overlapping, Journal of Educational Psychology (December, 1937), pp. 656-672.

Zweig, Jeanne, Individualism - A Recruiting Aid for Local Practitioners, Journal of Accountancy (November, 1969), pp. 90-92. 